\title{
Bone Turnover Markers and Adipocytokinesresponse to Weight Reduction among Obese Patients with Type 2 Diabetes Mellitus
}

\author{
Shehab M Abd El-Kader ${ }^{1 *}$ and Eman M Ashmawy ${ }^{2}$ \\ ${ }^{1}$ Department of Physical Therapy for Cardiopulmonary Disorders, Faculty of Physical Therapy, Cairo University, Egypt \\ ${ }^{2}$ Department of Physical Therapy, Faculty of Medical Rehabilitation Sciences, King Abdalaziz University, Jeddah, Saudi Arabia
}

\begin{abstract}
Background: Type 2 diabetes mellitus (T2DM) is a highly prevalent disease associated with increased the risk of fracture due to altered bone micro architecture and/or poor quality as key factors. Bone remodeling appears to be impaired among patients with T2DM as both markers of bone formation and markers of bone resorption are decreased when compared to healthy subjects.
\end{abstract}

Objective: This study aimed to detect if weight reduction modulates adipokines and markers of bone turnover among T2DM patients.

Material and Methods: Eighty obese patients with T2DM (46 men and 34 women), their age ranged from 40-53 years and their body mass index ranged from $30-36 \mathrm{~kg} / \mathrm{m}^{2}$ were equally assigned into 2 groups: the weight reduction group received aerobic exercises, diet regimen, where the control group received medical treatment only for 6 months.

Results: The mean values of body mass index (BMI), leptin, resistin, visfatin levels significantly decreased, however the mean values of adiponectin, bone alkaline phosphatase (BAP) and serum cross-linked N-telopeptides of type I collagen (NTX) levels significantly increased in the training group. While, the results of the control group were not significant. In addition, there were significant differences between both groups at the end of the study.

Conclusion: Weight loss ameliorates adipocytokines and bone turnover markers among obese patients with type 2 diabetes mellitus.

Keywords: Aerobic exercise, Bone turnover, Type 2 diabetes mellitus, Adipokines, Diet regimen

\section{Introduction}

Globally, Type 2 diabetes mellitus (T2DM) will reach 438 million by $2030 .{ }^{1}$ Bone damage is a common complication after diabetes mellitus. ${ }^{2,3}$ Despite there is an evidence that T2DM is related to poor bone quality and micro architecture that elevate the risk of bone fragility and fracture. ${ }^{4}$

Type 2 diabetes mellitus (T2DM) is a main cause for cardiovascular dysfunctions, ${ }^{5-7}$ the risk of coronary artery disease is 2-4 times among diabetics than non-diabetics and peripheral vascular diseases risk is ten times greater among diabetics than non-diabetics. $^{8,9}$

Bone turnover biomarkers (BTMs) indicate the bone remodeling status that includes both bone resorption and formation. ${ }^{9}$ There an impairment in bone remodeling among patients with diabetes, where bone formation biomarkers and bone resorption biomarkers are reduced. ${ }^{10-13}$ Although T2DM patients have higher bone marrow density (BMD), the fracture risk is higher among them. ${ }^{14,15}$ Therefore, BTMs are more sensitive markers than BMD for bone fracture
Quick Response Code:

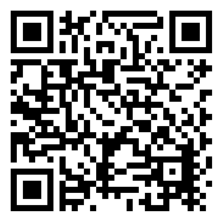

*Corresponding author: Shehab M Abd El-Kader, Department of Physical Therapy for Cardiopulmonary Disorders, Faculty of Physical Therapy, Cairo University, Egypt

Received: 28 July, 2021

Published: 11 August, 2021

Citation: Abd El-Kader SM, Ashmawy EM. Bone Turnover Markers and Adipocytokinesresponse to Weight Reduction among Obese Patients with Type 2 Diabetes Mellitus. SOJ Diabet Endocr Care. 2021;1(2):1-5. DOI: 10.53902/SOJDEC.2021.01.000506 
risk, due to possible link between blood glucose metabolism and BTMs. ${ }^{16,17}$

Bone turnover biomarkers are markers for measure rate of resorption and formation. Osteoblast is responsible for synthesis of bone formation biomarkers, so that reflect certain function of osteoblast ${ }^{18,19}$ that considered as bone formation markers which are predictors for hip fracture risk and osteoporosis. ${ }^{20-25}$

The purpose of this study was to determine the effects of weight reduction on bone turnover markers and adipocytokines among obese patients with T2DM.

\section{Materials and Methods}

\section{Subjects}

Eighty obese T2DM patients ( 46 men and 34 women) with body mass index (BMI) ranged from 30 to $36 \mathrm{Kg} / \mathrm{m}^{2}$, were selected from the outpatient diabetic clinic of the King Abdalziz Teaching Hospital. They were checked for fasting/random glucose levels. Only participants have fasting blood sugar levels more than $5.6 \mathrm{mmol} / \mathrm{l}$ or random blood sugar level more than $7.8 \mathrm{mmol} / \mathrm{l}$ (impaired blood sugar) were included in this study and were further checked for type 2 diabetes mellitus as per recent American Diabetes Association criteria. ${ }^{26}$ Exclusion criteria included smokers, congestive heart failure, pregnant female patients, hypertension, chronic liver disease, coronary artery disease, angiopathy, myocardial infarction, cerebral infarction and infectious disease. Subjects were also excluded from the study if they had conditions affecting bone metabolism, including kidney, liver, parathyroid, or thyroid disorders.

Physical examinations included anthropometric measurements such as height, weight, body mass index (BMI) and waist circumference. Participants were allocated randomly into two study groups; group (A) received treadmill aerobic exercise training on treadmill and diet regimen. However, group (B) received no intervention and was considered as a control group.

\section{Measurements}

\section{Serum adiponectin, leptin, resistin and visfatin mea- surement}

The levels of adiponectin in human serum were determined using adiponectin ELISA (Phoenix Pharmaceuticals, Inc., Belmont, CA). Serum leptin, resistin, and visfatin levels were detected using ELISA (Phoenix Pharmaceuticals).

\section{Bone turnover biochemical markers measurement}

The serum concentration of bone alkaline phosphatase (BAP) was measured with ELISA kits (BAP from Metra ${ }^{\mathrm{TM}}$ BAP EIA kit, Quidel Corp., San Diego, CA). In addition, Serum cross-linked N-telopeptides of type I collagen (NTX) level can serve as a marker of increased bone resorption, which may be present in diseases such as osteoporosis and BM. Serum cross-linked N-telopeptides of type
I collagen (NTX) was measured using an ELISA kit (Osteomark, Ostex, Inc., Seattle,WA). ${ }^{27}$

\section{Procedures}

\section{All participants were divided randomly into the follow- ing groups:}

Group (A): Forty type 2 diabetic patients were submitted to the aerobic exercise training to complete a 12 -week aerobic exercise on a treadmill which was conducted according to recommendation of American College of Sports Medicine regarding aerobic exercise application. ${ }^{28}$ Training program included 5 minutes for warming-up in the form of range motion and stretching exercises, 30 minutes of aerobic exercise training (60-70\% of maximum heart rate) and 10 minutes of cooling down (on treadmill with low speed and without inclination). Participants received 3 training sessions weekly for 6 months. In addition, a dietician supervised diet regimen that provides 1200 Kilocalories/day for 6 months.

Group (B): Forty type 2 diabetic patients of both sexes maintained their ordinary life style and received no intervention.

\section{Statistical Analysis}

Paired " $t$ " test used to compare between pre and posttest values. While, the unpaired " $t$ " test used for comparing between both groups $(\mathrm{P}<0.05)$.

\section{Results}

Obese T2DM patients were enrolled including 46 men and 34 women, had a mean age of $47.71 \pm 5.28$ year who were enrolled into two groups, there was no significant differences in body mass, glucose, index insulin resistant as indicated by values of insulin, HOMA-IR and value of QUICKI between both groups (Table 1).

Table 1: Baseline characteristics of all participants.

\begin{tabular}{|l|l|l|l|}
\hline \multirow{2}{*}{} & \multicolumn{2}{|c|}{ Mean+SD } & \multirow{2}{*}{ Significance } \\
\cline { 2 - 3 } Age year & \multicolumn{1}{|c|}{ Group (A) } & \multicolumn{1}{|c|}{ Group (B) } & \\
\hline Gender M/F & $24.32 \pm 4.98$ & $47.17 \pm 5.67$ & $\mathrm{P}>0.05$ \\
\hline BMI kg/m ${ }^{2}$ & $33.47 \pm 2.25$ & $32.73 \pm 2.12$ & $\mathrm{P}>0.05$ \\
\hline $\begin{array}{l}\text { Waist circum- } \\
\text { ference cm }\end{array}$ & $112.34 \pm 9.42$ & $110.11 \pm 8.93$ & $\mathrm{P}>0.05$ \\
\hline FBS $\mathrm{mg} / \mathrm{dl}$ & $173.15 \pm 10.18$ & $169.86 \pm 11.25$ & $\mathrm{P}<0.05$ \\
\hline PPS mg/dl & $231.24 \pm 15.12$ & $228.95 \pm 14.73$ & $\mathrm{P}<0.05$ \\
\hline Insulin mU/l & $14.83 \pm 3.46$ & $14.17 \pm 3.55$ & $\mathrm{P}<0.05$ \\
\hline QUICKI & $0.126 \pm 0.031$ & $0.135 \pm 0.027$ & $\mathrm{P}<0.05$ \\
\hline HOMA-IR & $5.64 \pm 1.83$ & $5.38 \pm 1.72$ & $\mathrm{P}<0.05$ \\
\hline HBA1c $\%$ & $8.79 \pm 2.66$ & $8.21 \pm 2.53$ & $\mathrm{P}<0.05$ \\
\hline
\end{tabular}

BMI: Body Mass Index; FBS: Fasting Blood Sugar; PPS: Postprandial Blood Sugar; HOMA-IR: Homeostasis Model Assessment-Insulin Resistance (HOMA-IR) Index; QUICKI: The quantitative insulin-sensitivity check index; HBA1c: glycosylated hemoglobin; $(*)$ indicates a significant difference between the two groups, $\mathrm{P}<0.05$. 
The mean values of body mass index (BMI), leptin, resistin, visfatin levels significantly decreased, however the mean values of adiponectin, bone alkaline phosphates (BAP) and serum crosslinked N-telopeptides of type I collagen (NTX) levels significantly increased in the training group (A) (Table 2 \& Table 3). While, the results of the control group (B) were not significant. In addition, there were significant differences between both groups at the end of the study (Table 4).

Table 2: Mean value and significance of BMI, adiponectin, leptin, resistin, visfatin, BAP and NTX in group (A) before and at the end of the study.

\begin{tabular}{|c|c|c|c|c|}
\hline & & $+\mathrm{SD}$ & T-value & Significance \\
\hline & Pre & Post & & \\
\hline BMI $\mathrm{kg} / \mathrm{m}^{2}$ & $33.47 \pm 2.25$ & $27.12 \pm 1.93^{*}$ & 6.78 & $\mathrm{P}<0.05$ \\
\hline Adiponectin $\mu \mathrm{g} / \mathrm{ml}$ & $6.84 \pm 1.41$ & $12.65 \pm 1.97^{*}$ & 5.42 & $\mathrm{P}<0.05$ \\
\hline Leptin $\mathrm{ng} / \mathrm{ml}$ & $23.16 \pm 3.11$ & $13.74 \pm 2.56^{*}$ & 5.17 & $\mathrm{P}<0.05$ \\
\hline Resistin $\mathrm{ng} / \mathrm{ml}$ & $7.38 \pm 1.54$ & $5.21 \pm 1.33^{*}$ & 4.92 & $\mathrm{P}<0.05$ \\
\hline Visfatin $\mathrm{ng} / \mathrm{mL}$ & $35.27 \pm 4.61$ & $22.35 \pm 3.55^{*}$ & 7.17 & $\mathrm{P}<0.05$ \\
\hline BAP U/l & $16.75 \pm 3.14$ & $27.92 \pm 3.67^{*}$ & 5.38 & $\mathrm{P}<0.05$ \\
\hline NTX nmol BCE & $13.15 \pm 3.26$ & $17.44 \pm 3.58^{*}$ & 6.23 & $\mathrm{P}<0.05$ \\
\hline
\end{tabular}

BMI: Body Mass Index; BAP: Bone Alkaline Phosphatase; NTX: Bone Cross-linked N-telopeptides of Type Collagen; $\left({ }^{*}\right)$ indicates a significant difference, $\mathrm{P}<0.05$.

Table 3: Mean value and significance of BMI, adiponectin, leptin, resistin, visfatin, BAP and NTX in group (B) before and at the end of the study.

\begin{tabular}{|c|c|c|c|c|}
\hline & \multicolumn{2}{|c|}{ Mean +SD } & \multirow[t]{2}{*}{ T-value } & \multirow[t]{2}{*}{ Significance } \\
\hline & Pre & Post & & \\
\hline BMI kg/m² & $32.73 \pm 2.12$ & $33.26 \pm 2.15$ & 1.17 & $\mathrm{P}>0.05$ \\
\hline Adiponectin $\mu \mathrm{g} / \mathrm{ml}$ & $7.14 \pm 1.37$ & $6.53 \pm 1.26$ & 0.82 & $\mathrm{P}>0.05$ \\
\hline Leptin $\mathrm{ng} / \mathrm{ml}$ & $22.75 \pm 2.88$ & $23.94 \pm 3.22$ & 1.15 & $\mathrm{P}>0.05$ \\
\hline Resistin ng/ml & $7.12 \pm 1.34$ & $7.81 \pm 1.45$ & 0.96 & $\mathrm{P}>0.05$ \\
\hline Visfatin ng/mL & $34.53 \pm 4.39$ & $35.86 \pm 4.72$ & 1.31 & $\mathrm{P}>0.05$ \\
\hline BAP U/l & $17.11 \pm 3.12$ & $15.94 \pm 3.06$ & 1.23 & $\mathrm{P}>0.05$ \\
\hline NTX nmol BCE & $13.49 \pm 3.14$ & $12.87 \pm 2.95$ & 1.12 & $\mathrm{P}>0.05$ \\
\hline
\end{tabular}

BMI: Body Mass Index; BAP: Bone Alkaline Phosphatase; NTX: Bone Cross-linked N-telopeptides of Type Collagen.

Table 4: Mean value and significance of BMI, adiponectin, leptin, resistin, visfatin, BAP and NTX in group (A) and group (B) at the end of the study.

\begin{tabular}{|l|l|l|l|l|}
\hline \multirow{2}{*}{} & \multicolumn{2}{|c|}{ Mean +SD } & \multirow{2}{*}{ T-value } & \multirow{2}{*}{ Significance } \\
\cline { 2 - 3 } & \multicolumn{1}{|c|}{ Group (A) } & \multicolumn{1}{|c|}{ Group (B) } & & \\
\hline BMI $\mathrm{kg} / \mathrm{m}^{2}$ & $27.12 \pm 1.93^{*}$ & $33.26 \pm 2.15$ & 7.22 & $\mathrm{P}<0.05$ \\
\hline Adiponectin $\mu \mathrm{g} / \mathrm{ml}$ & $12.65 \pm 1.97^{*}$ & $6.53 \pm 1.26$ & 6.14 & $\mathrm{P}<0.05$ \\
\hline Leptin $\mathrm{ng} / \mathrm{ml}$ & $13.74 \pm 2.56^{*}$ & $23.94 \pm 3.22$ & 5.78 & $\mathrm{P}<0.05$ \\
\hline Resistin $\mathrm{ng} / \mathrm{ml}$ & $5.21 \pm 1.33^{*}$ & $7.81 \pm 1.45$ & 5.31 & $\mathrm{P}<0.05$ \\
\hline Visfatin $\mathrm{ng} / \mathrm{mL}$ & $22.35 \pm 3.55^{*}$ & $35.86 \pm 4.72$ & 7.88 & $\mathrm{P}<0.05$ \\
\hline BAP U/l & $27.92 \pm 3.67^{*}$ & $15.94 \pm 3.06$ & 5.91 & $\mathrm{P}<0.05$ \\
\hline NTX nmol BCE & $17.44 \pm 3.58^{*}$ & $12.87 \pm 2.95$ & 6.78 & $\mathrm{P}<0.05$ \\
\hline
\end{tabular}

BMI: Body Mass Index; BAP: Bone Alkaline Phosphatase; NTX: Bone Cross-linked N-telopeptides of Type Collagen; $(*)$ indicates a significant difference between the two groups, $\mathrm{P}<0.05$.

\section{Discussion}

Diabetes mellitus is associated with an increased risk of fractures, which is not explained by bone mineral density. Other markers as bone turnover markers (BTMs) may be useful. Markers of bone resorption and formation seem to be lower in diabetes patients. ${ }^{29}$ As there is a growing interest in the association between diabetes and alterations in bone metabolism, this study aimed to investigate the effects of weight reduction on bone turnover markers and adipocytokines among obese patients T2DM. Our main result finding of the present study was that 6 months of weight reducing program resulted significant increase in BAP, NTX and adiponectin along with significant reduction in leptin, resist in and visfatin levels, these results are in line with many previous studies. 
Hinton and coworkers underwent 6 weeks of energy restriction and aerobic exercise to induce a 5\% reduction in body weight on 19 obese and overweight subjects and reported that markers of bone formation, osteocalcin, and bone alkaline phosphates, were significantly increased, and resorption markers, C-terminal cross-links of type I collagen and soluble receptor activator of nuclear factor kappa B ligand, were unchanged after 6 weeks of energy restriction and exercise and concluded that weight-bearing, aerobic exercise training may favorably affect the balance between bone resorption and formation during weight loss. ${ }^{30}$ While, Luceyetal. enrolled 276 overweight men and women in a strict hypo energetic diet for 8 weeks induced to have about $5 \%$ loss of body weight, their results stated that urinary $\mathrm{N}$-telopeptides of type I collagen and serum C-terminal telopeptide of type I collagen increased, whereas serum osteocalcin decreased from baseline to endpoint. ${ }^{31}$ However, Villareal and colleagues evaluated the effects of diet-induced weight loss in conjunction with exercise on bone metabolism and mass in twenty-seven obese older adults. They founded that after six months, serum CTX and serum osteocalcin concentrations increased in the treatment group but not in the control group, in the other hand there were no significant changes in serum bone alkaline phosphatase concentrations. $^{32}$ In addition, Rector and colleagues reported that $5 \%$ reduction in body weight over 6 weeks in 36 overweight premenopausal women resulted in a significant increase in level of both Osteocalcin (OC) and C-terminal telopeptide of type I collagen (CTX). ${ }^{33}$ Where, Hinton and colleagues stated that the thirty-seven obese subjects who underwent 3 months of weight reduction followed by 9 months weight maintenance had their serum concentrations of osteocalcin (OC) and C-terminal peptide of type I collagen (CTX) significantly increased after weight reduction and remained elevated during weight maintenance, moreover the percent changes in CTX and body weight were negatively correlated during weight loss and maintenance. ${ }^{34}$ Moreover, Maser and colleagues studied 32 individuals with a body mass index $50.2 \pm 10.2 \mathrm{~kg} / \mathrm{m}^{2}$ underwent Roux-en-Y gastric bypass and confirmed that there was an increase in both OC and adiponectin, where leptin was decreased 6 months after surgery. ${ }^{35}$ Finally, Albadah et al proved that significant reduction in $\mathrm{BMI}$ as a result of four-month dietary program among forty-nine obese nondiabetic males resulted in significant increase in serum BAP, adiponectin and undercarb oxylatedosteo calcin (uOC). ${ }^{36}$

\section{Conclusion}

Weight loss ameliorates adipocytokines and bone turnover markers among obese patients with type 2 diabetes mellitus.

\section{Acknowledgments}

None.

\section{Funding}

None.

\section{Conflicts of Interest}

Author declares that there is no conflict of interest.

\section{References}

1. Whiting DR, Guariguata L, Weil C, et al. IDF diabetes atlas: global estimates of the prevalence of diabetes for 2011 and 2030. Diabetes Res Clin Pract. 2011;94(4):311-321.

2. Carnevale V, Romagnoli E, D'Erasmo E. Skeletal involvement in patients with diabetes mellitus. Diabetes Metab Res Rev. 2004;20(3):196-204.

3. Merlotti D, Gennari L, Dotta F, et al. Mechanisms of impaired bone strength in type 1 and 2 diabetes. Nutr Metab Cardiovasc Dis. 2010;20(9):683-690.

4. Karim L, Bouxsein ML. Effect of type 2 diabetes-related non-enzymatic glycation on bone biomechanical properties. Bone. 2016;82:21-27.

5. Tak WW, Wong, Ling S, Yu TX, et al. Endothelial Dysfunction: The Common Consequence in Diabetes and Hypertension. J Cardiovasc Pharmacol. 2010;55(4):300-307.

6. Andreassi MG, Barale R, Iozzo P, et al. The association of micronucleus frequency with obesity, diabetes and cardiovascular disease. Mutagenesis. 2011;26(1):77-83.

7. International Diabetes Federation. Diabetes: a major risk factor.

8. Karasu C. Glycoxidative stress and cardiovascular complications in experimentally induced diabetes: effects of antioxidant treatment. Open Cardiovasc Med J. 2010;4:240-256.

9. Ding H, Triggle CR. Endothelial cell dysfunction and the vascular complications associated with type 2 diabetes: assessing the health of the endothelium. Vasc Health Risk Manag. 2005;1(1):55-71.

10. Devogelaer JP, Boutsen Y, Gruson D, et al. Is there a place for bone turnover markers in the assessment of osteoporosis and its treatment? Rheum Dis Clin N Am. 2011;37(3):365-386.

11. Oz SG, Guven GS, Kilicarslan A, et al. Evaluation of bone metabolism and bone mass in patients with type-2 diabetes mellitus. J Natl Med Assoc. 2006;98(10):1598-1604.

12. Gaudio A, Privitera F, Battaglia K, et al. Sclerostin levels associated with inhibition of the Wnt/beta-catenin signaling and reduced bone turnoverin type 2 diabetes mellitus. J Clin Endocrinol Metab. 2012;97(10):3744-3750.

13. Ardawi MS, Akhbar DH, Alshaikh A, et al. Increased serum sclerostin and decreased serum IGF-1 are associated with vertebral fractures among postmenopausal women with type-2 diabetes. Bone. 2013;56(2):355-62.

14. Gennari L, Merlotti D, Valenti R, et al. Circulating sclerostin levels and bone turnover in type 1 and type 2 diabetes. J Clin Endocrinol Metab. 2012;97(5):1737-1744.

15. Jac kuliak P, Payer J. Osteoporosis, fractures, and diabetes. Int J Endocrinol. 2014;2014:820615.

16. Starup Linde J, Eriksen SA, Lykkeboe S, et al. Biochemical markers of bone turnover in diabetes patients-a meta-analysis, and a methodological study on the effects of glucose on bonemarkers. Osteoporos Int. 2014;25(6):1697-1708.

17. Clemens TL, Karsenty G. The osteoblast: an insulin target cell controlling glucose homeostasis. J Bone Miner Res. 2011;26(4):677-680.

18. Kindblom JM, Ohlsson C, Ljunggren 0 , et al. Mellstrom, Plasma osteocalcin is inversely related to fat mass and plasma glucose in elderly Swedish men.J Bone Miner Res. 2009;24(5):785-791.

19. PD Delmas, Eastell R, Garnero P, et al. The use of biochemical markers of bone turnover in osteoporosis. Committee of Scientific Advi- 
sors of the International Osteoporosis Foundation. Osteoporos Int. 2000;11(Suppl 6):S2-S17.

20. Lee AJ, Hodges S, Eastell R. Measurement of osteocalcin. Ann Clin Biochem. 2000;37(Pt 4):432-446.

21. Garnero P, Sornay Rendu E, Chapuy MC, et al. Increased bone turnover in late postmenopausal women is a major determinant of osteoporosis. J Bone Miner Res. 1996;11(3):337-349.

22. Lofman O, Magnusson P, Toss G, et al. Common biochemical markers of bone turnover predict future bone loss: a 5-year follow-up study. Clin Chim Acta. 2005;356(1-2):67-75.

23. Pi YZ, Wu XP, Liu SP, et al. Age-related changes in bone biochemical markers and their relationship with bone mineral density in normal Chinese women.J Bone Miner Metab. 2006;24(5):380-385.

24. Yoshimura N, Muraki S, Oka H, et al. Akune, Biochemical markers of bone turnover as predictors of osteoporosis and osteoporotic fractures in men and women: 10-year follow-up of the Taiji cohort. Mod Rheumatol. 2011;21(6):608-620.

25. Szulc P, Chapuy MC, Meunier PJ, et al. Serum under carboxylated osteocalcin is a marker of the risk of hip fracture in elderly women. J Clin Invest. 1993;91(4):1769-1774.

26. American Diabetes Association. Diagnosis and classification of diabetes mellitus. Diabetes Care. 2010;33(Suppl 1):S62-S69.

27. Kress BC. Bone alkaline phosphatase: methods of quantitation and clinical utility. J Clin Ligand Assay. 1998;21(2):139-148.

28. American College of Sports Medicine. Guidelines for graded exercise testing and exercise prescription, Lea \& Febiger, Philadelphia; 2005.
29. Starup-Linde J, Vestergaard P. Biochemical bone turnover markers in diabetes mellitus-A systematic review. Bone. 2016;82:69-78.

30. Hinton PS, Rector RS, Thomas TR. Weight-bearing, aerobic exercise increases markers of bone formation during short-term weight loss in overweight and obese men and women. Metabolism. 2006;55(12):1616-1618.

31. Lucey AJ, Paschos GK, Cashman KD, et al. Influence of moderate energy restriction and seafood consumption on bone turnover in overweight young adults. Am J Clin Nutr. 2008;87(4):1045-1052.

32. Villareal DT, Shah K, Banks MR, et al. Effect of weight loss and exercise therapy on bone metabolism and mass in obese older adults: a one-year randomized controlled trial. J ClinEndocrinol Metab. 2008;93(6):2181-2187.

33. Rector RS, Loethen J, Ruebel M, et al. Serum markers of bone turnover are increased by modest weight loss with or without weight-bearing exercise in overweight premenopausal women. Appl Physiol Nutr Metab. 2009;34(5):933-941.

34. Hinton PS, Le Cheminant JD, Smith BK, et al. Weight loss-induced alterations in serum markers of bone turnover persist during weight maintenance in obese men and women. J Am Coll Nutr. 2009;28(5):565573.

35. Maser RE, James Lenhard M, Balagopal PB, et al. Effects of surgically induced weight loss by Roux-en-Y gastric bypass on osteocalcin. Surgery for obesity and related diseases. 2013;9(6):950-955.

36. Albadah MS, Dekhil H, Shaik SA, et al. Effect of weight loss on serum osteocalcin and its association with serum adipokines. Int J Endocrinol. 2015;2015:508-532. 